\title{
Avaliação ultra-sonográfica do volume do líquido amniótico
}

\author{
Sergio Kobayashi ${ }^{1}$
}

Com o estudo do líquido amniótico (LA) podemos obter importantes informações sobre a integridade funcional, citogenética e estrutural do concepto. É um importante indicador do estado da vitalidade fetal. $\mathrm{O}$ estudo do volume do LA tem fundamental importância na avaliação da morbidade e mortalidade perinatais, identificação de anomalias congênitas, predição de crescimento intra-uterino restrito e insuficiência placentária.

A composição do LA muda com a idade gestacional, sendo que no início da gravidez o líquido é isotônico em relação ao sangue materno e fetal, representando um transudato do trofoblasto ou feto. Com a queratinização da pele fetal, ao redor de 23/25 semanas de gestação, a passagem de líquido através da pele fetal fica bastante reduzida. Neste período, a urina fetal é mais hipotônica do que no início da gestação, e o LA torna-se hipotônico em relação ao sangue fetal. Com o amadurecimento da função renal fetal o LA torna-se progressivamente mais diluído e a osmolaridade diminui.

$\mathrm{O}$ acesso ao estudo deste compartimento pela ultra-sonografia revolucionou a medicina fetal, permitindo avanços importantes na avaliação da vitalidade fetal, assim como do seu desenvolvimento anatômico, principalmente em gestações de alto risco. Todavia, ainda não é possível o cálculo preciso do volume do LA por meio das técnicas ultra-sonográficas.

Apesar do estudo do volume do LA ser procedimento de rotina no acompanhamento gestacional, ainda não há consenso de qual método é o mais acurado e preditivo de morbidade perinatal. Existem controvérsias sobre qual é o melhor método ultra-sonográfico para a avaliação do volume do LA.

As principais funções do LA são: dissipação das forças uterinas aplicadas sobre o feto, minimizar o gasto de energia para os movimentos fetais essenciais ao seu desenvolvimento, termorregulação, suporte ao crescimento fetal e uterino, propriedades bacteriostáticas, prevenção da compressão do cordão umbilical, depósito de excretas fetais e melhora da acuidade ultra-sonográfica.

É importante conhecer e compreender as principais vias de produção e reabsorção do LA. A regulação e o equilíbrio do volume do LA é um processo dinâmico que demonstra o balanço entre a produção e a reabsorção, envolvendo vários mecanismos interdependentes entre o concepto, a placenta, as membranas e o organismo materno. A detecção de alterações do volume do LA, em qualquer fase da gestação, deve

1. Médico Assistente Doutor do Instituto de Radiologia do Hospital das Clínicas da Faculdade de Medicina da Universidade de São Paulo. ser prontamente investigada tanto do ponto de vista fetal quanto materno. As principais vias de produção são: a transudação pela pele fetal, pela superfície placentária e pelo cordão umbilical; o fluido traqueal; a urina fetal; a saliva e o suor fetal. E a principal via de eliminação do LA é por meio da deglutição fetal.

O volume do LA muda com a idade gestacional, aumentando progressivamente de oito semanas até cerca de 33/34 semanas de gestação. Após este período existe um leve declínio até o termo da gestação.

O aumento dramático do número de gestações múltiplas e dos seus problemas associados tem fortalecido questões relacionadas ao melhor método para avaliar o volume do LA nestas gestações.

Com o advento da ultra-sonografia tridimensional e da ressonância magnética talvez possamos resolver dilemas quanto à reprodutibilidade e à precisão da medida do volume do LA, necessitando de mais estudos.

Os principais métodos de avaliação do volume do LA são:

1 - Método subjetivo: este método é totalmente dependente da experiência do ultra-sonografista.

2 - Métodos semiquantitativos:

a) Técnica da medida do maior bolsão vertical (MBV) Introduzida por Chamberlain et al. ${ }^{(1)}$, que mede o maior bolsão vertical, livre de cordão e partes fetais, visualizado por meio da ultra-sonografia. Considera-se normal quando o maior bolsão mede entre $20 \mathrm{~mm}$ e $80 \mathrm{~mm}$. Esta técnica tem a vantagem de ser simples e reprodutível, e provavelmente a melhor técnica para avaliação do LA em gestações múltiplas.

b) Índice do líquido amniótico (ILA) - Introduzido por Phelan et al. ${ }^{(2)}$, utiliza a medida do maior bolsão vertical em cada um dos quatro quadrantes do útero. $\mathrm{O}$ transdutor deve ser posicionado no plano sagital da paciente e perpendicular ao seu plano coronal. Deve-se tomar o cuidado de não angular o transdutor para acomodar à curvatura do útero. As medidas de cada bolsão devem estar livres de alças de cordão e partes fetais. Bolsões muito pequenos, menores de $5 \mathrm{~mm}$, não devem ser medidos. Em 1990, Moore e Cayle ${ }^{(3)}$ descreveram uma curva de normalidade, com respectivos desvios-padrão para cada idade gestacional, em que o ILA maior que o percentil 95 indica polidrâmnio e menor que o percentil 5 indica oligoidrâmnio.

c) Técnica da medida bidimensional do maior bolsão (MBMB) - Introduzida por Magann et al. ${ }^{(4)}$, multiplica a medida do maior diâmetro vertical utilizando-se a técnica do MBV pelo maior diâmetro horizontal. O bolsão escolhido deve 
estar livre de alças de cordão e partes fetais. Os valores de normalidade são definidos entre $15,1 \mathrm{~cm}$ e $50,0 \mathrm{~cm}$.

As técnicas ultra-sonográficas para a medida do volume de LA (MBV, ILA e MBMB) representam tentativas de aplicar um valor numérico ao volume do LA por meio da ultrasonografia. A estimativa do volume do LA não é fácil devido ao formato irregular da cavidade amniótica e aos movimentos corpóreos fetais. Até o momento, o ILA é o método mais aceito para avaliar o volume do LA em gestações únicas e o que melhor reflete o volume do $\mathrm{LA}^{(5)}$. A relação entre os métodos de avaliação do volume do LA e o volume efetivo é bastante próxima ${ }^{(6,7)}$, mostrando que quaisquer destes métodos, desde que realizados com rigor técnico, são eficientes e fidedignos. A avaliação subjetiva para a detecção de alterações do volume do LA apresenta sensibilidade tão boa quanto as técnicas semiquantitativas, desde que realizadas por profissionais treinados e qualificados. O Doppler com mapeamento em cores auxilia evidenciar a presença de cordão umbilical nos bolsões de LA, principalmente nos casos de oligoidrâmnio, já que apenas os bolsões livres podem ser medidos e contabilizados (Figura 1).

O diagnóstico precoce de alteração grave do volume do LA pode, em casos selecionados, possibilitar o tratamento e profilaxia de complicações perinatais com procedimentos invasivos como a amnioinfusão e a amniodrenagem ${ }^{(8)}$.

Nestes últimos anos a ultra-sonografia com tecnologia tridimensional vem avançando progressivamente, entre eles no quesito de cálculo volumétrico. A maioria dos trabalhos está focada no estudo do volume fetal, por exemplo, na estimativa do peso fetal. Existem poucos relatos na literatura médica estudando a estimativa do volume do LA. O estudo tridimensional do volume do LA parece correlacionar-se bem com o ILA e a área bidimensional. Portanto, a ultra-sonografia 3D pode se tornar importante método propedêutico na avaliação do LA, entretanto mais estudos são necessários.

Um importante aspecto refere-se à freqüência recomendada para reavaliação do LA. Lagrew et al. ${ }^{(9)} \mathrm{e}$ Wing et al. ${ }^{(10)}$ mostraram que o ILA normal antes de 41 semanas de gestação estava associado a menos de $0,5 \%$ de chance de desenvolver oligoidrâmnio nos quatro dias subseqüentes. Em casos de ILA limítrofes o risco de oligoidrâmnio varia de 5\% a $18 \%$.

Em artigo original publicado anteriormente, Costa et al. ${ }^{(11)}$ descreveram estudo prospectivo analisando o ILA em gestantes de baixo risco que apresentaram ou não complicações na gestação ou período neonatal. Esses autores concluíram que o ILA em gestações de baixo risco não parece ser um bom preditor de complicações tanto no período gestacional quanto perinatal. Minha opinião em relação a este trabalho é que o número de gestantes participantes pudesse ser ampliado e mais de um observador realizasse o ILA em cada exame realizado. Este é um trabalho bastante interessante e a linha de pesquisa a respeito do LA deve ser incentivada.

Podemos concluir que o estudo do volume do LA é um importante componente da avaliação ultra-sonográfica em obstetrícia, tanto no momento anteparto como intraparto. É

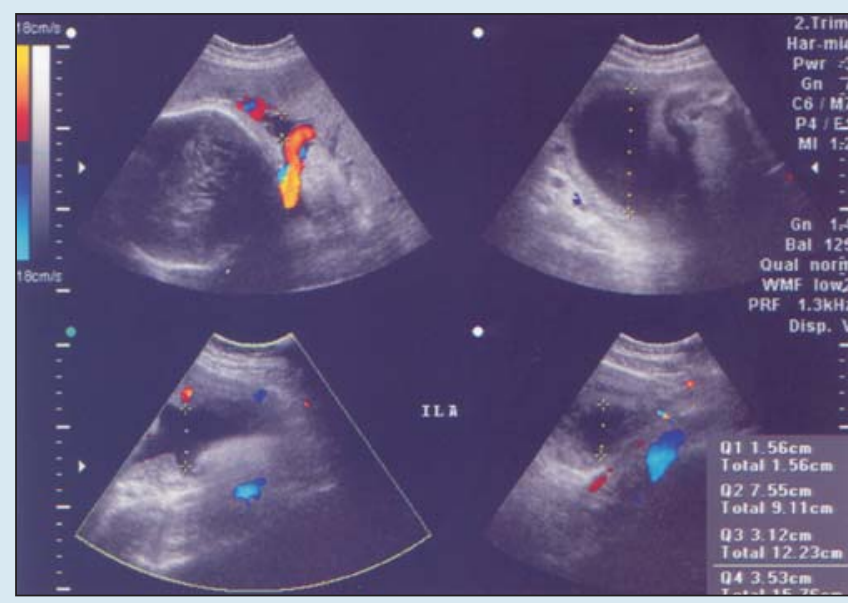

Figura 1. Medida do ILA com auxílio do Doppler em cores.

considerado tempo obrigatório no exame ultra-sonográfico obstétrico. É importante salientar que o valor clínico da ultra-sonografia não é estimar o valor absoluto do LA, mas de identificar quais pacientes estão fora dos valores de normalidade esperados para a idade gestacional e no seguimento destas gestações. Existem ainda pontos obscuros na avaliação do volume do LA por meio da ultra-sonografia, portanto é muito importante que mais estudos sejam realizados para podermos alcançar maiores níveis de sensibilidade e especificidade para o diagnóstico e seguimento das alterações do volume de LA.

\section{REFERÊNCIAS}

1. Chamberlain PF, Manning FA, Morrison I, Harman CR, Lange IR. U1trasound evaluation of amniotic fluid volume. I. The relationship of marginal and decreased amniotic fluid volumes to perinatal outcome. Am J Obstet Gynecol 1984;150:245-254.

2. Phelan JP, Ahn MO, Smith CV, Rutherford SE, Anderson E. Amniotic fluid index measurements during pregnancy. J Reprod Med 1987;32: 601-604.

3. Moore TR, Cayle JE. The amniotic fluid index in normal human pregnancy. Am J Obstet Gynecol 1990;162:1168-1173.

4. Magann EF, Nolan TE, Hess LW, Martin RW, Whitworth NS, Morrison JC. Measurement of amniotic fluid volume: accuracy of ultrasonography techniques. Am J Obstet Gynecol 1992;167:1533-1537.

5. Schrimmer DB, Moore TR. Sonographic evaluation of amniotic fluid volume. Clin Obstet Gynecol 2002;45:1026-1038.

6. Croom CS, Banias BB, Ramos-Santos E, Devoe LD, Bezhadian A, Hiett AK. Do semiquantitative amniotic fluid indexes reflect actual volume? Am J Obstet Gynecol 1992;167(4 Pt 1):995-999.

7. Dildy GA 3rd, Lira N, Moise KJ Jr, Riddle GD, Deter RL. Amniotic fluid volume assessment: comparison of ultrasonographic estimates versus direct measurements with a dye-dilution technique in human pregnancy. Am J Obstet Gynecol 1992;167(4 Pt 1):986-994.

8. Kobayashi S. Amnioinfusão - indicações e técnica. In: Guias de medicina ambulatorial e hospitalar. São Paulo: Unifesp/EPM - Obstetrícia, 2003.

9. Lagrew DC, Pircon RA, Nageotte M, Freeman RK, Dorchester W. How frequently should the amniotic fluid index be repeated? Am J Obstet Gynecol 1992;167(4 Pt 1):1129-1133.

10. Wing DA, Fishman A, Gonzalez C, Paul RH. How frequently should the amniotic fluid index be performed during the course of antepartum testing? Am J Obstet Gynecol 1996;174(1 Pt 1):33-36.

11. Costa FS, Cunha SP, Berezowski AT. Avaliação prospectiva do índice de líquido amniótico em gestações normais e complicadas. Radiol Bras 2005;38:337-341. 